\title{
Assessing Ethical Issues in Tax Agencies in Mongolia
}

\author{
Oyunbileg Pagjii, Suvdaa Damiran \\ Finance Department, National University of Mongolia, Ulaanbaatar, Mongolia \\ Email: oyunbileg_p@num.edu.mn,d.suvdaa@num.edu.mn
}

How to cite this paper: Pagjii, O., \& Damiran, S. (2021). Assessing Ethical Issues in Tax Agencies in Mongolia. iBusiness, 13, 103-115.

https://doi.org/10.4236/ib.2021.132007

Received: April 29, 2021

Accepted: June 4, 2021

Published: June 7, 2021

Copyright $\odot 2021$ by author(s) and Scientific Research Publishing Inc. This work is licensed under the Creative Commons Attribution International License (CC BY 4.0).

http://creativecommons.org/licenses/by/4.0/

\section{(c) (i) Open Access}

\begin{abstract}
The primary goal of this study is to assess practices and services provided by tax agencies from an ethical standpoint, to research and evaluate the impact of the ethical problems on supporting businesses, to compare the findings with practices in other public administration agencies and to identify areas for improvement. The findings of the study indicate that: 1) Regarding the suitability of tax services for business environment, it currently looks not very supportive for business entities although it does appear to be average or slightly above average; 2) Six indicators of tax service ethics are carefully examined: knowledge and skills of tax staff; their interpersonal skills and ethics; consistency of rules on corruption and bribery within tax agencies; bureaucracy; and relationships among departments and units. When the data are combined and represented at the national level, in UB city and local population, the findings indicate that tax agencies demonstrate indicators of moderate ethical problems when compared to those of other government bodies across the country; 3) As the impact assessment of the above six indicators implies, interpersonal skills and inter-departmental relationship indicators in tax agencies in UB, knowledge and skills, interpersonal skills, and ethics indicators in the case of local tax agencies demonstrate having impact as the regressive equation suggests; 4) When ethics in tax agencies are thoroughly examined in terms of corruption, bribery and bureaucracy and their nationwide, UB city and local population aggregate distribution are presented, no indicators of corruption and bribery affecting the operations and services of tax agencies are observed; however, as regression equation recommends, a bureaucratic impact is detected.
\end{abstract}

\section{Keywords}

Tax Administration, Taxpayers' Satisfaction, Tax Service Quality, Bureaucracy Index, Public Officials' Ethics, Human Resource Management, Tax Reform 


\section{Introduction}

Mongolia's economy is dependent on natural resources, is highly vulnerable to commodity price fluctuations and external factors, and is a small open economy. Due to the global Covid-19 pandemic, the economic growth of the country has slowed, unemployment and poverty have increased, foreign direct investment has decreased, and business incomes have been reduced. Therefore, the government is implementing a policy aimed at supporting businesses, protecting the health of its citizens, and supporting real purchasing power. Mongolia's tax system has been overhauled for the second time in the 30 years following the country's transition to a market economy, or after the new tax system was established. Customer satisfaction became a critical factor in enhancing the efficiency and accessibility of government services and addressing service-related issues in the twenty-first century. In recent years, the country's government agencies, especially the tax agencies, have prioritized taxpayer satisfaction and have been implementing new strategies, methods, and reforms in their modern tax services. In reality, however, our research shows that improving the efficiency and accessibility of tax services, improving the ethics of public officials, and eliminating corruption and bureaucracy are still pressing concerns. Using the example of tax agencies, we will discuss the ethical problems faced by public servants and officials, as well as their effect on business operations, and compare them to other government agencies. A multi-stage, random sampling method was used to perform the survey. The survey included 1202 enterprises and organizations out of 63,028 in Ulaanbaatar and 2873 enterprises and organizations out of 31,792 in the local areas, with UB agencies accounting for $30 \%$ of the total participants and those in the local region accounting for $70 \%$. The study employed quantitative research techniques such as statistical analysis, comparison, correlation analysis, regression analysis, and analyzing and synthesizing methods.

Besides the importance of a favorable business climate, stakeholders' ethics, especially the quality and accessibility of public services, bureaucracy, and corruption, all have a significant impact. In order to determine the factors that influence bureaucracy, the Mongolian National Chamber of Trade and Industry conducted a Bureaucracy Index in 2015 and 2018 (Industry, 2018). Furthermore, countries all over the world are researching the bureaucratic index and introducing policies and initiatives to eradicate it. In particular, the Bureaucracy Index is a simple and transparent quantification of the proverbial "red tape", which is often mentioned by the media, but rarely in any quantitative terms. On average, an entrepreneur spent 140 hours on red tape in 2016 (Studies, 2016). Today, in order to run a business both globally and domestically, it is important to 1) stick to global ethical standards; 2) respect the culture and values of others; and 3) comply with corporate ethics (Becker, 2019). The impact on the businesses by the public organization services and the indicators including ethics, interpersonal skills, bureaucracy, and corruption of the staff, on the other hand, is often analyzed at the international level and countries are ranked and reported 
on how they build a favorable business climate (Bank, 2020). In a study surveyed over 400 corporate tax officials from more than 50 countries on tax ethics and its implementation, $13 \%$ of the respondents answered that they have a tax code of conduct in place and it is publicly available, $48 \%$ stated that they have a tax code of conduct for internal use, and $38 \%$ reported that they have no formal tax code of conduct (KPMG, 2018). This shows that the code of ethics is not open to the public and is not sufficiently enforced. Mongolian Government has been undertaking substantial reforms in restructuring and modernizing the revenue administration to provide equitable, efficient and effective services to taxpayers. The renewal of the tax administration, in particular, was initiated as part of the tax reform that started in 2020. The tax agencies have segmented the services given to taxpayers into high, medium, small and micro levels as part of this reform, and have established a policy based on that, which is different from previous tax reforms. In other words, reforms have been made to cover tax administration services such as taxpayer registration, taxation, exemptions, tax payment, reporting, and monitoring (Suvdaa, 2019). Personnel with strong ethical and communicative principles, as well as broad expertise and competent skills, are critical for tax reform implementation. Ethics is an essential part of public service work and maintaining the integrity of democratic institutions (Kommer, 2012). Effective human resource management is a key requirement for the tax agencies and plays an important role in generating tax revenue and fulfilling its core responsibilities. Furthermore, as globalization expands and international transactions develop, tax laws become more complex, as do taxpayer demands and expectations, and the world in which tax administration and law enforcement services operate changes rapidly.

As Claus states, revenue authorities need an adequate number of highly skilled, trustworthy, and well-trained professionals. In some countries with large population revenue authorities seem to be understaffed. Furthermore, certain revenue bodies devote relatively little resources to human resources (Claus, 2014).

\section{Research and Outcomes}

\subsection{Assessment of Tax Activities and Services}

When a one-sided T-Test is used to test a sample that evaluates the performance of a tax authority with a value of more than 4 or a zero hypothesis that the service is good, the T-Test has a high negative value $(-69.8)$ and a significance level of 0 . As a result, our initial assumptions were refuted and businesses did not evaluate the performance of the tax agencies as good. Table 1 shows the assessment results of appropriateness of services of tax agencies and Graph 1 shows the histogram.

Graph 1 shows that the average value of the tax agencies' performance and services is nearly approached the median (2.96), the distribution values are shifted to the side that is rated as good, and there is little standard deviation. 
Further, the evaluation of this indicator was calculated in detail for the Ulaanbaatar and local area sets, and the results are shown in Graph 2 and Graph 3, respectively.

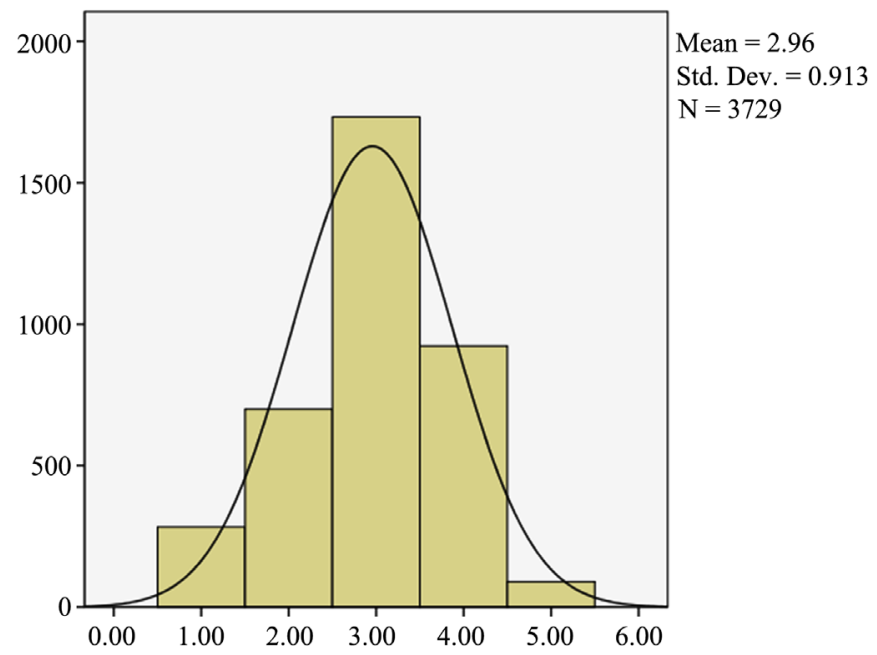

Graph 1. Appropriateness of tax agency service/frequency/.

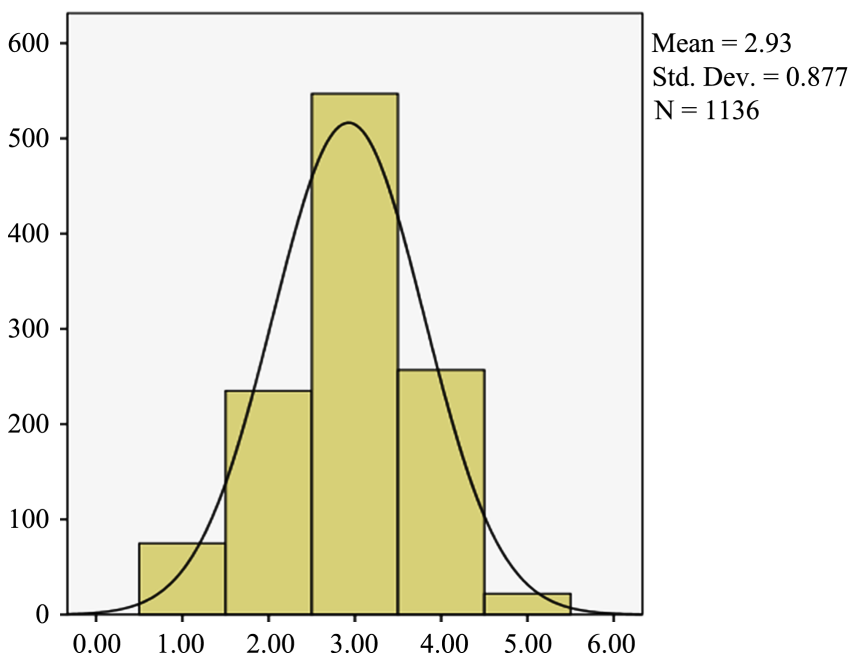

Graph 2. Appropriateness of tax agency service/Ulaanbaatar city, frequency/.

Table 1. Appropriateness of tax agency service /frequency/.

\begin{tabular}{ccccc}
\hline & Frequency & Percent & Valid Percent & Cumulative Percent \\
\hline Most Appropriate & 283 & 6.9 & 7.6 & 7.6 \\
Appropriate & 700 & 17.2 & 18.8 & 26.4 \\
Neutral & 1733 & 42.5 & 46.5 & 72.8 \\
Less Appropriate & 923 & 22.7 & 24.8 & 97.6 \\
Not Appropriate & 90 & 2.2 & 2.4 & 100.0 \\
N & 3729 & 91.5 & 100.0 & \\
Missing & 346 & 8.5 & & \\
\hline
\end{tabular}

Source: estimation by researchers. 


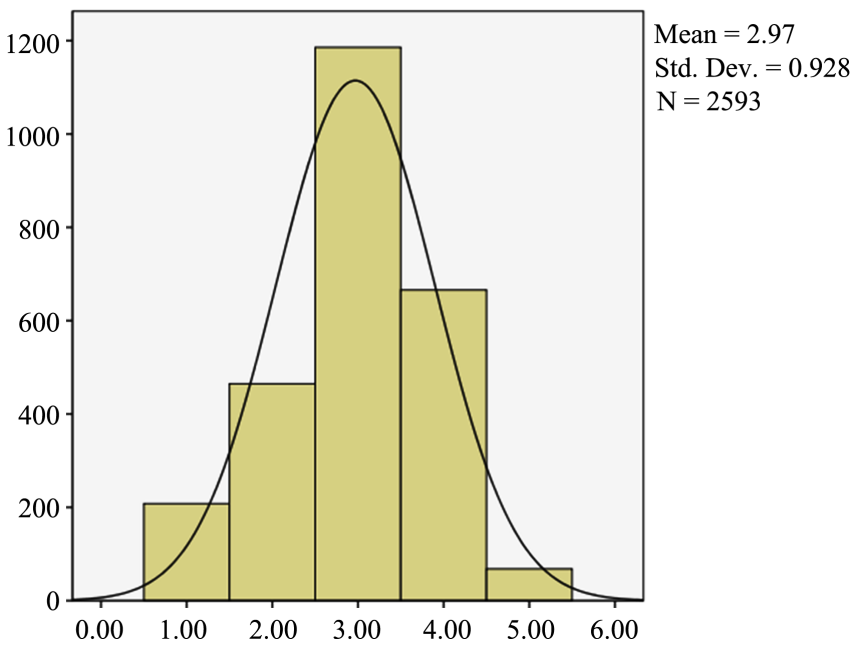

Graph 3. Appropriateness of tax agency service/Local area, frequency/.

These graphs show that the average rating for UB agencies is 2.93 while the average rating of local agencies appears very close to the median (2.97), with a normal distribution and shifted to a rating of good.

Summarizing these results, businesses rated the activities and services of the tax agencies as moderate at the national level and better at the local level.

\subsection{Results of Considering the Activities and Services of the Tax Agencies from the Ethical Point of View in 6 Indicators Are as Follows}

This assesses the knowledge and skills of tax officials (X1), their communication and ethics (X2), corruption and bribery in tax agencies (X3), clarity of rules (X4), bureaucracy (X5), and inter-departmental relationships (X6). The aim is to look at the six indicators (Association $\mathrm{X} 6$ ) in detail and to present aggregate distribution at the national level, in UB and local areas.

To do this, we first considered the correlation of these parameters, and the results are presented in Table 2.

Table 2 shows that the indicators related to the knowledge and skills of tax officials are highly correlated with their interpersonal skills and ethics (0.85), and the relations between departments and units are highly correlated with the clarity of regulations (0.8), while the weakest indicator correlated with corruption and knowledge and skills (0.55) as well as corruption and communication and ethics (0.56). Bureaucracy, on the other hand, is more correlated with other indicators than corruption and bribery. Therefore, we considered these indicators as appropriate to do the evaluation. In doing this evaluation, we compared these indicators with those of other public service organizations. Table 3 shows how the X1 to X6 indicators cause barriers and difficulties to public service organizations nationwide and they are exposed in percentage. The higher the percentage, the more obstacles and challenges are faced by businesses due to practices provided by the public agengies and the lower the percentage, the less the obstacles and challenges. 
Table 2. Correlations of indicators.

\begin{tabular}{|c|c|c|c|c|c|c|c|}
\hline & & $\begin{array}{l}\text { knowledge } \\
\text { and skills }\end{array}$ & $\begin{array}{l}\text { communication } \\
\text { and ethics }\end{array}$ & $\begin{array}{l}\text { corruption } \\
\text { and bribery }\end{array}$ & $\begin{array}{l}\text { clarity } \\
\text { of rules }\end{array}$ & bureaucracy & $\begin{array}{l}\text { inter-departmental } \\
\text { relationships }\end{array}$ \\
\hline knowledge and skills & & 1 & 0.85 & 0.55 & 0.76 & 0.72 & 0.74 \\
\hline communication and ethics & & 0.85 & 1 & 0.56 & 0.76 & 0.75 & 0.74 \\
\hline corruption and bribery & Pearson & 0.55 & 0.56 & 1 & 0.63 & 0.66 & 0.63 \\
\hline clarity of rules & Correl. & 0.76 & 0.76 & 0.63 & 1 & 0.78 & 0.8 \\
\hline bureaucracy & & 0.72 & 0.75 & 0.66 & 0.78 & 1 & 0.76 \\
\hline inter-departmental relationships & & 0.74 & 0.74 & 0.63 & 0.8 & 0.76 & 1 \\
\hline Sig. (2-tailed) & & 0.0 & 0.0 & 0.0 & 0.0 & 0.0 & \\
\hline $\mathrm{N}$ & & 4075 & 4075 & 4075 & 4075 & 4075 & 4075 \\
\hline
\end{tabular}

Source: estimation by researchers.

Table 3. Barriers and difficulties businesses face due to public organizations /percent/.

\begin{tabular}{|c|c|c|c|c|c|c|}
\hline & $\begin{array}{l}\text { knowledge } \\
\text { and skills }\end{array}$ & $\begin{array}{l}\text { communication } \\
\text { and ethics }\end{array}$ & $\begin{array}{l}\text { corruption } \\
\text { and bribery }\end{array}$ & $\begin{array}{l}\text { clarity } \\
\text { of rules }\end{array}$ & bureaucracy & $\begin{array}{l}\text { inter-departmental } \\
\text { relationships }\end{array}$ \\
\hline Ministries & $26 \%$ & $34 \%$ & $51 \%$ & $32 \%$ & $52 \%$ & $45 \%$ \\
\hline Local Government & $27 \%$ & $30 \%$ & $43 \%$ & $28 \%$ & $42 \%$ & $38 \%$ \\
\hline Specialized Inspection Agency & $22 \%$ & $31 \%$ & $45 \%$ & $26 \%$ & $41 \%$ & $35 \%$ \\
\hline Tax Authority & $17 \%$ & $24 \%$ & $34 \%$ & $21 \%$ & $33 \%$ & $27 \%$ \\
\hline Standardization and Metrology Agency & $15 \%$ & $18 \%$ & $25 \%$ & $17 \%$ & $24 \%$ & $22 \%$ \\
\hline Land Office & $30 \%$ & $39 \%$ & $52 \%$ & $35 \%$ & $49 \%$ & $39 \%$ \\
\hline Registration Authority (company / civil/ property) & $17 \%$ & $24 \%$ & $25 \%$ & $18 \%$ & $26 \%$ & $21 \%$ \\
\hline Police & $23 \%$ & $32 \%$ & $38 \%$ & $25 \%$ & $36 \%$ & $27 \%$ \\
\hline Customs, & $26 \%$ & $34 \%$ & $44 \%$ & $28 \%$ & $42 \%$ & $32 \%$ \\
\hline Border Authority & $26 \%$ & $34 \%$ & $40 \%$ & $29 \%$ & $38 \%$ & $31 \%$ \\
\hline Department of Construction and Urban Planning & $28 \%$ & $34 \%$ & $39 \%$ & $28 \%$ & $38 \%$ & $31 \%$ \\
\hline
\end{tabular}

Source: estimation by researchers.

The tax agencies are rated at the national average, according to Table 3. The main contributors were corruption and bribery (34\%), bureaucracy (33\%), and inter-departmental relationships (27\%). As a result, lowering these rates would enable the tax agencies to eliminate barriers for businesses.

This was evaluated involving each of the six indicators, with 1 being very bad, 2 being bad, 3 being moderate, 4 being good, and 5 being very good, and the weighted average was calculated thoroughly by each government agency at the national, UB city, and local levels. Table 4 displays the scores, which range from the easiest to the most challenging obstacles. Here, when we weighed the values of the survey responses, the best values are rated as the highest; therefore, as illsutrated in Table 4, the high-rated organizations cause less barriers and difficulties to businesses, whereas low-rated organizations bring on more barriers and difficulties to them. 
Table 4. Barriers and challenges businesses face due to public organizations /in weighted mean/.

\begin{tabular}{cccc}
\hline & Nationwide & UB city & Local Area \\
\hline Standardization and Metrology Agency & 3.18 & 2.99 & 3.25 \\
Registration Authority (company /civil/ property), & 3.14 & 3.02 & 3.19 \\
Tax Authority & 3.01 & 2.81 & 3.11 \\
Police & 2.96 & 2.82 & 3 \\
Department of Construction and Urban Planning & 2.86 & 2.67 & 2.94 \\
Specialized Inspection Agency & 2.85 & 2.55 & 2.98 \\
Border Authority & 2.85 & 2.67 & 2.93 \\
Customs, & 2.83 & 2.7 & 2.91 \\
Local Government & 2.79 & 2.45 & 2.88 \\
Land Office & 2.67 & 2.4 & 2.76 \\
Ministries & 2.66 & 2.46 & 2.8 \\
Average & 2.91 & 2.72 & 2.99 \\
\hline
\end{tabular}

Source: estimation by researchers.

According to Table 4, the national average is 2.91 , UB City is 2.72 , and local areas are rated at 2.99. The Ministries (2.66) and the Land Office (2.67) are regarded as causing the most obstacles and challenges among government departments. These results can be linked to the findings in Table 3, in which corruption and bribery is rated $51 \%$ for the ministries and $52 \%$ for Land Office, bureaucracy is $52 \%$ for the ministries and $49 \%$ for the Land office, and interdepartmental relationship is $45 \%$ for the ministries and $39 \%$ for the Land Office. As for tax agencies, the assessment of barriers they induce to businesses is rated as average at the national level (3.01), in UB (2.81) as well as at the local level (3.11).

As the findings of the Mongolian Business Environment Survey (Industry, 2017) conducted in 2017 suggested, the average value was 2.4 at that time; however, the current survey result demonstrates 3.01, which indicates an increase of 0.6 points. The main factor that contributed to this increase can be linked to the outcomes of some actions being implemented in the scope of tax administration reform and computerization.

\subsection{The Findings of a Comparative Review of the Effect of Six Indicators on Tax Agency Operations and Services}

We investigated whether a regression equation with different variables in terms of indicators X1 to X6 could be used to assess the activities and services of a tax agency. The StepWise approach was used to test the model in Table 5, which looked at tax activities and services as independent variables and X1 to X6 measures as dependent variables. 
Table 5. Model of indicators influencing tax operations and services.

\begin{tabular}{ccccc}
\hline Model & $\mathrm{R}$ & R Square & Adjusted R Square & Std. Error of the Estimate \\
\hline 1 & $0.264^{\mathrm{a}}$ & 0.069 & 0.069 & 0.88090 \\
2 & $0.267^{\mathrm{b}}$ & 0.071 & 0.071 & 0.88024 \\
\hline
\end{tabular}

a. Predictors: (Constant), communication and ethics. b. Predictors: (Constant), communication and ethics, inter-departmental relationships.

Table 5 shows that the model was not significantly scored $(\mathrm{R} 2=0.071)$. The key explanation for this was the high rate of "don't know" responses to each indicator's assessment. In Graph 4, the responses "do not know" are highlighted in red in percentage.

Because of the high percentage of "don't know" responses for each of the six indicators, it can be concluded that businesses are not ready to be assessed in terms of tax agency ethics. Therefore, tax agencies should pay attention to the high rate of this response and are highly recommended that they consider transparency in their operations in order to minimize it.

As the second model in Table 5 displays, only two of the six indicators we assess in this study, namely communication and ethics (X2) and inter-departmental relationship (X6), can explain the ethics of tax service, which is rated at 7.1 percent. Table 6 displays the statistics for this model.

The following is how to write the equation using coefficients for the nationwide case:

$$
Y_{\text {Nationwide }}^{1}=0.170 \times 2+0.041 \times 6+2.422
$$

$Y_{\text {Nationwide }}^{1}-$ Tax activities and services, $\mathrm{x} 2$-communication and ethics, x6-inter-departmental relationships.

It can be inferred that a one-point improvement in tax officials' service and ethics would result in a 0.170 -point increase in services, as well as a one-point increase in services and a 0.041 -point increase in inter-departmental relationships nationally.

The model shown in Table 7 was tested for each of the above estimates for UB and the Local Area.

The statistics for this model are shown in Table 8.

The following is how to write the equation using coefficients for UB city and Local area cases:

$$
Y_{u b}^{2}=0.2 \times 2+0.084 \times 6+2.217
$$

$Y_{u b}^{2}-$ Tax activities and services, $\mathrm{x} 2$-communication and ethics, $\mathrm{x} 6$-inter-departmental relationships:

$$
Y_{\text {local }}^{2}=0.054 \times 1+0.134 \times 2+2.478
$$

$Y_{\text {local }}^{2}-$ Tax activities and services, $\mathrm{x} 1-$ knowledge and skills, $\mathrm{x} 2-$ communication and ethics.

This demonstrates that in the case of UB, the indicators for the relationship between interpersonal skills, ethics, and inter-departmental relationships 
Table 6. Model statistics /nationwide/.

\begin{tabular}{|c|c|c|c|c|c|c|}
\hline \multirow{2}{*}{ Model } & & \multicolumn{2}{|c|}{ Unstand. Coeff. } & \multirow{2}{*}{$\frac{\text { Standard. Coeff. }}{\text { Beta }}$} & \multirow{2}{*}{$\mathrm{t}$} & \multirow{2}{*}{ Sig. } \\
\hline & & B & Std. Error & & & \\
\hline \multirow{2}{*}{1} & (Constant) & 2.446 & 0.034 & & 72.319 & 0.00 \\
\hline & communication and ethics & 0.200 & 0.012 & 0.264 & 16.676 & 0.00 \\
\hline \multirow{3}{*}{2} & (Constant) & 2.422 & 0.035 & & 69.124 & 0.00 \\
\hline & communication and ethics & 0.170 & 0.016 & 0.225 & 10.379 & 0.00 \\
\hline & inter-departmental relationships & 0.041 & 0.016 & 0.056 & 2.557 & 0.01 \\
\hline
\end{tabular}

Dependent Variable: Tax activities and services.

Table 7. Model of tax activities and services influenced by indicators /by scope/.

\begin{tabular}{ccccc}
\hline & $\mathrm{R}$ & $\mathrm{R}$ Square & Adjusted R Square & Std. Error of the Estimate \\
\hline \multirow{2}{*}{ UB city } & $0.318^{\mathrm{a}}$ & 0.101 & 0.100 & 0.83237 \\
& $0.328^{\mathrm{b}}$ & 0.107 & 0.106 & 0.82969 \\
\hline \multirow{2}{*}{ Local Area } & $0.244^{\mathrm{a}}$ & 0.060 & 0.059 & 0.90010 \\
& $0.248^{\mathrm{c}}$ & 0.062 & 0.061 & 0.89932 \\
\hline
\end{tabular}

a. Predictors: (Constant), communication and ethics b. Predictors: (Constant), communication and ethics, inter-departmental relationships c. Predictors: (Constant), communication and ethics, knowledge and skills.

Table 8. Model statistics /by scope/.

\begin{tabular}{|c|c|c|c|c|c|c|c|}
\hline & & & \multicolumn{2}{|c|}{ Unstand. Coeff. } & \multirow{2}{*}{$\begin{array}{c}\text { Stand. Coeff. } \\
\text { Beta }\end{array}$} & \multirow{2}{*}{$\mathrm{t}$} & \multirow{2}{*}{ Sig. } \\
\hline & & & B & Std. Error & & & \\
\hline \multirow{5}{*}{ UB city } & & (Constant) & 2.270 & 0.000 & & 35.939 & 0.000 \\
\hline & & communication and ethics & 0.256 & 0.000 & 0.318 & 11.277 & 0.000 \\
\hline & & (Constant) & 2.217 & 0.000 & & 33.773 & 0.000 \\
\hline & 2 & communication and ethics & 0.200 & 0.000 & 0.248 & 6.678 & 0.000 \\
\hline & & inter-departmental relationships & 0.084 & 0.004 & 0.107 & 2.888 & 0.004 \\
\hline \multirow{5}{*}{$\begin{array}{l}\text { Local } \\
\text { area }\end{array}$} & & (Constant) & 2.507 & 0.000 & & 62.439 & 0.000 \\
\hline & & communication and ethics & 0.179 & 0.000 & 0.244 & 12.832 & 0.000 \\
\hline & & (Constant) & 2.478 & 0.000 & & 59.039 & 0.000 \\
\hline & 2 & communication and ethics & 0.134 & 0.000 & 0.182 & 5.591 & 0.000 \\
\hline & & knowledge and skills & 0.054 & 0.019 & 0.077 & 2.347 & 0.019 \\
\hline
\end{tabular}

Dependent Variable: Tax activities and services.

represented tax activities and services as expressed in Equation (2), whereas in local areas, those for the relationship between knowledge, skills, interpersonal skills, and ethics representing the tax practices and services are expressed in Equation (3). 


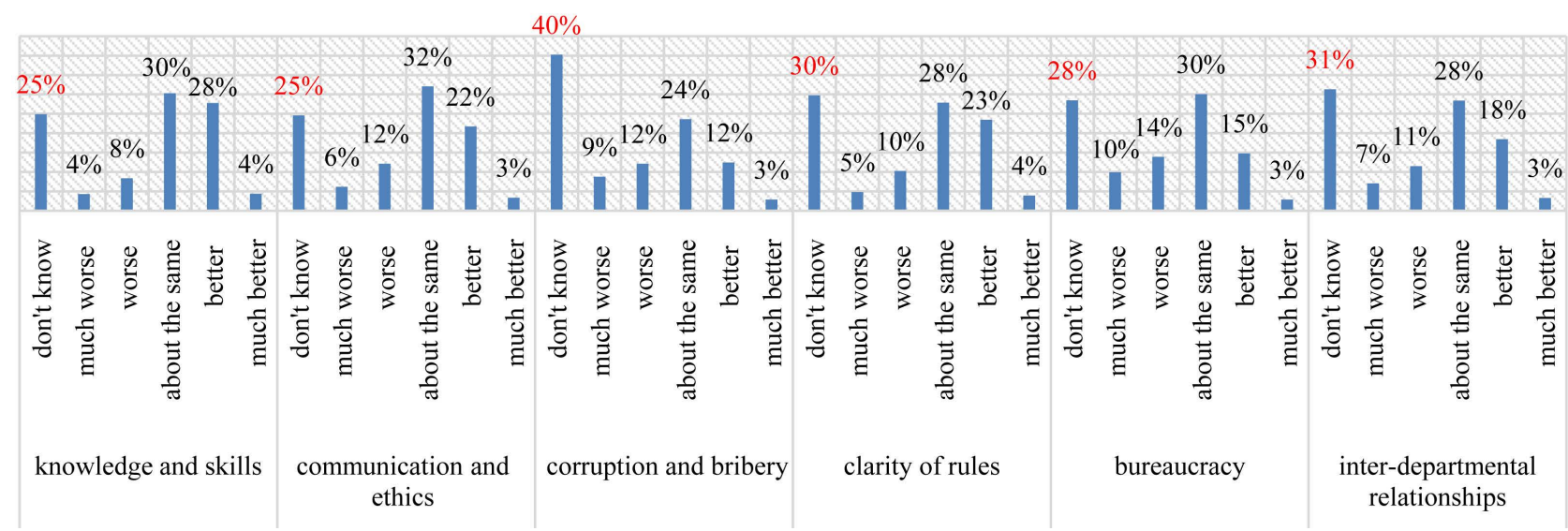

Graph 4. Obstacles and challenges businesses face due to tax agencies /percentage/. Source: estimation by researchers.

\subsection{The Findings of a Comparative Study of the Impact of Six Indicators on the Activities and Services of Tax Agencies}

We will now investigate and assess the impact of the tax authorities' corruption, bribery (X3), and bureaucracy (X5) indicators, which were excluded from the previous models. Table 9 depicts a model that illustrates the impacts of these two indicators.

Table 9 shows that in the evaluation of tax services, the impact of corruption and bureaucracy on tax agencies can be explained by 2.5 percent. To assess the model's conformity, the equation can be considered appropriate based on statistical results in which the $\mathrm{F}$ characteristic is 48,268 and the significance level tends to 0 . The statistics for this model are shown in Table 10.

As shown in Table 10, corruption and bribery indicators ( $\mathrm{Sig}=0.27$ ) are excluded from the model. The following is how to write the equation:

$$
Y_{\text {Nationwide }}^{3}=0.103 \times 5+2.767
$$

$Y_{\text {Nationwide }}^{3}$ - Tax activities and services, bureaucracy (X5).

According to the methodology described above, corruption and bribery indicators ( $\mathrm{Sig}=0.748$ ) were excluded from the Ulaanbaatar model, whereas corruption indicators $(\mathrm{Sig}=0.277)$ from the local model.

Based on statistical results of 19,880 for the Ulaanbaatar model and 30,435 for the local model, with a significance level of 0 , the equation $\mathrm{F}$ can be considered appropriate for evaluating models conformity.

Using the coefficients assessed here, the model was evaluated by (5) and (6) equations as follows:

$$
Y_{u b}^{3}=0.124 \times 5+2.675
$$

$Y_{u b}^{3}-$ Tax activities and services, bureaucracy $(X 5)$ :

$$
Y_{\text {local }}^{3}=0.098 \times 5+2.798
$$

$Y_{\text {local }}^{3}$ - Tax activities and services, bureaucracy (X5).

The fact that corruption indicators have no effect on performance of tax agencies supports our conclusion that companies in other sections of our sample are not yet ready to make this assessment. 
Table 9. Model influenced by indicators of corruption, bribery and bureaucracy in tax services.

\begin{tabular}{ccccc}
\hline Model & $\mathrm{R}$ & R Square & Adjusted R Square & Std. Error of the Estimate \\
\hline 1 & $0.159^{\mathrm{a}}$ & 0.025 & 0.025 & 0.90169 \\
\hline
\end{tabular}

a. Predictors: (Constant), bureaucracy, corruption and bribery.

Table 10. Statistics for evaluating corruption and bureaucratic impact model.

\begin{tabular}{|c|c|c|c|c|c|c|c|c|}
\hline & \multirow{2}{*}{ Model } & \multicolumn{2}{|c|}{ Unstand. Coeff. } & \multirow[t]{2}{*}{ Stand. Coeff. } & \multirow{2}{*}{$\mathrm{t}$} & \multirow{2}{*}{ Sig. } & \multicolumn{2}{|c|}{$\begin{array}{l}95.0 \% \text { Confidence } \\
\text { Interval for B }\end{array}$} \\
\hline & & B & Std. Error & & & & $\begin{array}{l}\text { Lower } \\
\text { Bound }\end{array}$ & $\begin{array}{l}\text { Upper } \\
\text { Bound }\end{array}$ \\
\hline \multirow{3}{*}{1} & (Constant) & 2.767 & 0.025 & & 110.498 & 0.0 & 2.718 & 2.816 \\
\hline & $\begin{array}{l}\text { corruption } \\
\text { and bribery }\end{array}$ & -0.013 & 0.012 & -0.023 & -1.103 & 0.270 & -0.037 & 0.010 \\
\hline & bureaucracy & 0.103 & 0.013 & 0.173 & 8.146 & 0.0 & 0.078 & 0.128 \\
\hline
\end{tabular}

\section{Conclusion}

Mongolian Government has been undertaking substantial reforms in reforming and modernizing the revenue administration to provide equitable, efficient and effective service to taxpayers. Mongolia's government has been implementing significant reforms in revenue administration in order to provide taxpayers with equitable, efficient, and effective service.

Specifically, reforms in tax administration operations were made, in particular, as part of the tax reform that began in 2020. Unlike previous tax reforms, the tax agencies that provide services to companies have segmented taxpayers into big, medium, small, and micro, and created policies based on that segmentation. In other words, tax agency operations and services such as taxpayer registration, taxation, exemptions, tax payment, reporting, and tracking are all being reformed. The competence of the tax agency, including skilled human resources, is important in the implementation of any tax policy or reform. As a result, one of the challenges facing tax agencies is to improve tax professionals' knowledge and skills, to build an ethical and honest human resource, and to have management policies and plans in place. The results of the study lead to the following conclusions:

1) It is commendable that the level of service provided by the tax agencies tends to increase from medium to slightly higher than medium in the business environment. On the other hand, this average level of ethical issues in tax agencies should be considered in comparison to other public administration entities, and measures should be implemented to boost this outcome.

2) The business entities provided a high percentage of "don't know" responses on each of the six main indicators when evaluating the tax agencies' service ethics; as a result, the tax agencies need to take better steps to increase taxpayer awareness of their services and promote their activities. 
3) Given the importance of the six ethical indicators, it is worthwhile for tax agencies to consider the outcomes of assessments by businesses on their staff's knowledge, skills, interpersonal skills, and ethics and take appropriate measures to improve the value of other indicators.

4) The assessment of tax services is unaffected by indices of corruption and bribery. As a result, when evaluating taxpayer satisfaction, tax authorities should pay attention to and track these indicators.

5) Policymakers should pay close attention to the operations of the revenue office, specifically its implementation regarding service delivery and tax reform policies in the country in order to fulfill the intended goal of addressing taxpayer satisfaction and ensuring good governance in the revenue sector by providing fair, reliable, and high-quality service to businesses.

The following recommendations were made to the General Tax Authority of Mongolia based on the study findings. These include the following:

1) Create a mechanism and system to monitor the implementation of the Codes of Conduct for Tax Officials and Civil Servants. There are two approaches to strengthening the ethical accountability of government agencies and avoiding unethical acts in current international practice: compliance-based approach and integrity-based approach, which our tax authorities must use in combination.

2) According to the study, the tax officials' knowledge and skills (17\%) and interpersonal skill and ethics (24\%) were assessed unsatisfactorily; therefore, it is suggested that tax agencies develop and implement tax specialist training, professional development, and human resource policies, as well as the tax administration's long-term program and planning. In addition, it is necessary to learn from the best international practices in personnel policy. For example, the Japanese tax authority has a good practice of having a tax college under its jurisdiction that regularly conducts training and capacity building for the human resources. The Mongolian tax authority could learn from this experience.

3) Create an evaluation system to assess performance of tax specialists based on customer satisfaction and productivity. As the current practices in Mongolia suggest, tax agencies are currently funded solely by program-based budgeting. Yet, the level of service and the end result of the specialist's work, on the other hand, are impossible to be evaluated without considering the factors such as their knowledge and skills; communication ethics; exposure to corruption and bribery and bureaucracy. As a result, it is suggested that these indicators be factored into a performance-based budgeting scheme.

In this study, we assessed the quality and accessibility of tax authorities' services based on customer satisfaction, which had some limitations. It is possible to extend the study in the future and conduct a systematic analysis of efficient tax service performance, tax compliance costs, and tax administration costs.

\section{Conflicts of Interest}

The authors declare no conflicts of interest regarding the publication of this paper. 


\section{References}

Bank, W. (2020). Doing Business 2020: Ease of Doing Business Score and Ease of Doing Business Ranking. Washigton: World Bank Group.

Becker, C. U. (2019). Business Ethics: Methods and Application. New York: Routledge Taylor \& Francis Group.

Claus, S. A. (2014). A Comparative Analysis of Tax Administration in Asia and the Pacific. Manila: $\mathrm{ADB}$.

Industry, M. N. (2017). Business Environment Survey. Ulaanbaatar: Mongolian National Chamber of Trade and Industry.

Industry, M. N. (2018). Bureaucracy Index. Ulaanbaatar: MNCTI.

Kommer, V. V. (2012). Integrity-Ethics for Tax Administrations. New York: IBFD.

KPMG. (2018). Global Tax Department Benchmarking. Amsterdam:KPMG International.

Studies, I. O. (2016). Slovak Bureaucracy Index. Bratislava: Institute of Economic and Social Studies.

Suvdaa, D. B. N. (2019). Tax Policy Reform It's Implementation in Mongolia. Money and Finance, 2, 5-12. 